\title{
artículos
}

\section{Los poblados que no existieron: Proyectos fallidos del Instituto Nacional de Colonización en Córdoba}

\author{
Pablo Rabasco Pozuelo \\ Universidad de Córdoba
}

\section{RESUMEN}

La delegación de Córdoba del Instituto Nacional de Colonización llevó a cabo entre 1941 y 1972, la construcción de diecisiete nuevas poblaciones donde trabajaron arquitectos de la talla de Antonio Fernández Alba, José Luis Fernández del Amo, Carlos Arniches o Fer nando de Terán. Pero la historia de este proceso, aunque quedó cristalizada en estos nuevos poblados, fue mucho más compleja. En este artículo analizaremos lo planificado, aquellos poblados que se diseñaron pero que no llegaron nunca a realizarse. Hablamos de proyectos que se plantearon fundamentalmente en los primeros años de existencia del Instituto, cuando no estaban claras muchas de las líneas de actuación, no sólo a nivel urbanístico o arquitectónico, sino fundamentalmente de ocupación del territorio y de acción social. Este estudio trata de analizar un total de doce nuevas poblaciones que nunca llegaron a construirse, pero que quedaron dibujadas y proyectadas.

PALABRAS CLAVE: Colonización/ poblados/ arquitectura del franquismo. \section{de Colonización (Córdoba) \\ ABSTRACT \\ This article is about twelve Unsuccessful Projects made by Instituto Nacional de} Colonización (INC) for several Settlements in the province of Córdoba (Spain) between 19411972.

KEY WORDS: Colonization/ settlements/ architecture of Franco years.

El Instituto Nacional de Colonización construyó en España más de doscientos nuevas poblaciones desde su creación en el año 1939. El proyecto de colonización tenía unos claros fines económicos, fundamentalmente la puesta en riego y la mejora productiva de buena parte del territorio español, y fue lugar de experimentación en muchos campos donde destacan especialmente la arquitectura y el urbanismo. $Y$ aunque es cierto que en este magno proyecto trabajaron algunos de los más destacados arquitectos de la España del siglo XX, también intervienen en él un buen número de arquitectos que no entenderán los encargos recibidos como un lugar para la innovación, sino, todo lo contrario, para construir poblaciones de corte historicista al amparo de un regionalismo confuso. Del mismo modo, se planificó mucho más de lo que se llegó a construir, y en ese punto nos detenemos, en el interés por recoger algunos de los poblados que llegaron a diseñarse pero que por diversas causas

* RABASCO POZUELO, Pablo: "Los poblados que no existieron: Proyectos fallidos del Instituto Nacional de Colonización en Córdoba", en Boletín de Arte $n^{\circ} 32-33$, Departamento de Historia del Arte, Universidad de Málaga, 2011-2012, págs. 591-611. Fecha de recepción: Abril de 2010. 


\begin{tabular}{|c|c|}
\hline 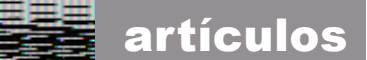 & Pablo Rabasco Pozuelo \\
\hline
\end{tabular}

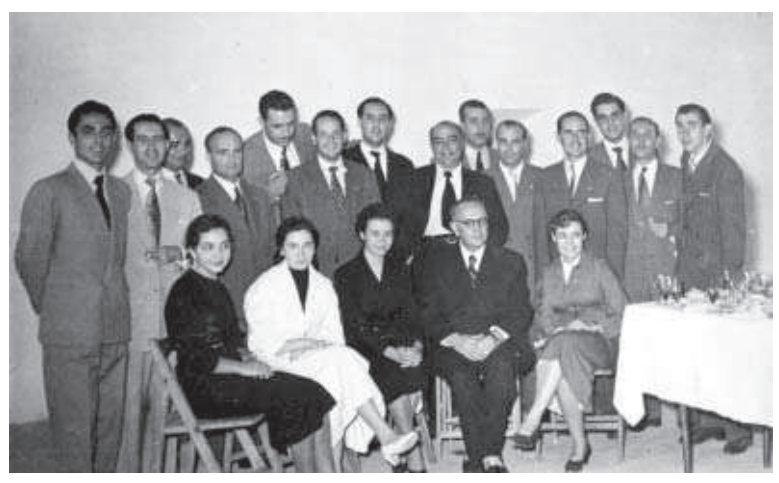

1. Personal de la Delegación de Córdoba.

no fueron nunca construidos. Será en este tipo de proyectos en los que podremos comprender los intereses y las ideas que fluyeron por el instituto, siendo finalmente algunas de ellas las que marcaron el camino a seguir y otras las que se quedaron en simples intentos, fallidos diseños que no llegaron nunca a construirse, pero que se han conservado en los fondos de los diferentes archivos.

\section{La delegación de Córdoba.}

La delegación de Córdoba del Instituto Nacional de Colonización ${ }^{1}$, creada en 1940, estuvo dirigida desde el momento de su creación por el ingeniero agrónomo Francisco Beato, como Ingeniero Jefe del servicio, cargo que ocuparía durante más de veinte años cuando ya en la década de los 70 le sustituyera en el puesto el también ingeniero agrónomo Francisco Lafuente Macchini. El equipo de trabajo de la delegación no fue demasiado amplio, estando compuesto por el ingeniero jefe, el arquitecto Francisco Giménez de la Cruz, el aparejador Felipe de la Fuente, tres ingenieros que eran Carlos Cremades, Guillermo Castañón y Francisco Pizarro, unos seis peritos agrícolas, tres delineantes y el personal del departamento de administración

Posteriormente, tras el fallecimiento de Francisco Giménez de la Cruz a principios de la década de los 60, el Instituto estuvo unos años sin arquitecto titular, recibiendo los proyectos arquitectónicos desde Madrid. Son las experiencias de arquitectos tan reconocidos como José Luis Fernández del Amo, Fernando de Terán o Antonio Fernández Alba, que participaron en la aventura del INC sin ser arquitectos por oposición del Instituto, recibiendo diferentes encargos por parte de éste. A éstos habría que sumar las colaboraciones de arquitectos de otras delegaciones que intervinieron en algunos de los proyectos bajo la responsabilidad de la delegación de Córdoba como son, Jesús Ayuso Tejerizo, Manuel Rosado o Jiménez Varea. Del mismo modo, los arquitectos y técnicos de la delegación cordobesa colaboraron en ocasiones con otras delegaciones en proyectos puntuales [1].

1 A partir de ahora INC. 
2. Zona Regable del Canal de la margen izquierda del Genil.

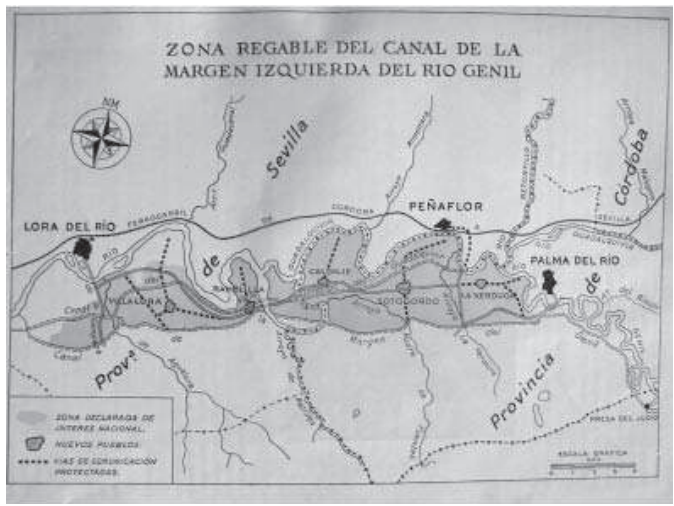

LA PLANIFICACIÓN SOBRE LA MARgEN IZqUIERDA del GeNIL.

La historia de la colonización desarrollada por la delegación del Instituto Nacional de Colonización en Córdoba comienza en el actual término municipal de Palma del Río y puede fecharse a partir de la declaración de esta zona, perteneciente al canal de la margen izquierda del río Genil, como de interés nacional por Decreto del Ministerio de Agricultura con fecha 25 de noviembre de 1940, publicado en el Boletín Oficial de 10 de diciembre de ese mismo año. Año y medio más tarde, el 30 de marzo de 1942, se encargó la redacción del Proyecto General de Colonización al ingeniero Guillermo Castañón Albertos y al arquitecto Jiménez Varea² [2].

Dicho proyecto fue aprobado por Orden del Ministerio de Agricultura un 25 de abril de $1944^{3}$. En éste, se trata de una manera íntegra toda la zona afectada por el canal de riego que parte de la margen izquierda del río Genil y que afecta a las poblaciones de Palma del Río, Lora del Río y Peñaflor. Pero como en la redacción del mismo se prevé una metodología basada en la división de este territorio en distintos sectores para su mejor estudio, no será hasta julio de 1947 cuando se redacte en Sevilla el Proyecto ordinario de colonización del sector III de la zona regable del canal de la margen izquierda del Genil, realizado por los ingenieros Juan de Lens y Antonio Montoya. Este proyecto se centró en un territorio donde no sólo se construyó finalmente el poblado de Calonge, sino que del mismo modo se estudió seriamente la construcción de otros poblados y núcleos rurales ${ }^{4}$.

2 CASTAÑÓN ALBERTOS, G, y JIMÉNEZ VAREA: Proyecto General de Colonización de la Margen Izquierda del Genil., Madrid, 30 de julio de 1942, Archivo de la Delegación del INC en Córdoba. Jiménez Varea ganó el concurso oposición para arquitecto del Instituto y pasó a formar parte de la nómina de cinco arquitectos que de alguna manera iniciaron la labor dentro del INC (BOE de 18 de octubre de 1941). Además de la dirección de este trabajo por los firmantes, colaboraron en la redacción del proyecto los ingenieros agrónomos de la delegación de Córdoba Juan Cano Martínez y Antonio Pizarro Checa, los peritos agrícolas funcionarios del Estado, Román Muñoz Alberca y Evaristo Padrós junto al aparejador Jesús Pastor.

3 CASTAÑÓN ALBERTOS, G: "Colonización de Grandes Zonas. Zona del Genil”, Colonización, diciembre, $\mathrm{n}^{\circ}$ 4, Madrid, 1945, págs. 92-98.

4 DE LENS, J. y MONTOYA, A: Proyecto Ordinario de Colonización del Sector IIl de la Zona Regable del 
Los otros subsectores fueron estudiados y planificados por el ingeniero agrónomo Antonio Pizarro (subsector $n^{\circ} 1$ ) y por el también ingeniero agrónomo Juan Cano Martínez (subsector $\left.n^{\circ} 2\right)^{5}$.

Realmente, a la hora de estudiar los numerosos documentos derivados de estas publicaciones nos damos cuenta de que los proyectos llevados a cabo el INC en esta zona son un porcentaje mínimo en relación a las estructuras planificadas, tanto a nivel agrícola, de infraestructuras como urbanístico, pues se pretendía una intervención mucho más ambiciosa. Como idea básica a tratar destaca el hecho de que Calonge no se planificó como una población concentrada, tal y como hoy la vemos, y que junto a La Verduga se concibieron ambas como núcleos rurales diseminados. Igualmente se planteó la construcción del pueblo de Sotogordo aunque nunca llegó a realizarse, pero del que se conservan las indicaciones para su ordenación urbana, dibujos a mano alzada del arquitecto Jiménez Varea y los proyectos completos que realizó más tarde el arquitecto José García Nieto 6 .

Los proyectos afectaban de la misma manera a la cercana y limítrofe localidad de Lora del Río (Sevilla), donde se diseñó el nuevo pueblo de Villalora que tampoco llegó a construirse, junto al núcleo rural de Ramblilla que igualmente no se llevó a cabo.

\section{Calonge, Ramblilla y la Verduga. Núcleos rurales dispersos.}

Ante el deseo finalmente frustrado por parte de las instituciones de llevar a cabo el proyecto de transformación de la zona, para lo que se necesitaba una gran cantidad de recursos humanos y económicos, se optó por agrupar a los colonos en dos tipos de formaciones urbanas: poblados y núcleos rurales. Estudiar estas dos tipologías por separado resulta complejo pues ambas se relacionan y en cierto modo presentan dependencias.

En el caso de los núcleos rurales dispersos definidos en el proyecto, Calonge, Ramblilla y La Verduga, se justifican teniendo en cuenta los problemas que presentan las viviendas aisladas. Inconvenientes como las dificultades para el abastecimiento del agua potable, evacuación de las aguas residuales, la falta de servicios básicos de abastecimiento, aislamiento social y un aumento del coste del proyecto a causa del mayor número de caminos rurales que este tipo de dispersión necesita.

Pero ante estos inconvenientes se valora positivamente el tiempo que el agricultor iba a ganar al estar viviendo junto a la parcela donde realiza su trabajo diario, sin tener que hacer desplazamientos penosos que a la larga podían conducir a la familia a abandonar el poblado de origen y construir un hogar más próximo a las zonas de regadío. Es más,

Canal de la Margen Izquierda del Genil. Sevilla, Julio de 1947, Archivo de la Delegación del INC en Córdoba. 5 PIZARRO, A: Proyecto de Colonización del Subsector Sector $n^{\circ} 1$ de la Zona regable del Canal (m. i.) del Río Genil. Documento $n^{\circ}$ 1. Memoria. Córdoba, Octubre de 1942, Archivo de la Delegación del INC en Córdoba.

6 GARCÍA NIETO, J: Sotogordo. Anteproyecto. Junio de 1945, Archivo de la Delegación del INC en Córdoba, y GARCÍA NIETO, J: Proyecto del Núcleo Rural La Verduga. Noviembre de 1945, Archivo de la Delegación del INC en Córdoba. 
esta formación urbana se complementa por la presencia cercana del nuevo pueblo de Sotogordo, situado a menos de seis kilómetros de ambos núcleos rurales, donde los colonos que ocupan las viviendas dispersas podrían desplazarse para desarrollar su vida social, espiritual y abastecerse de aquellos productos que les fueran necesarios ${ }^{7}$.

Igualmente, en un punto centralizado dentro de la zona de los núcleos rurales de La Verduga y Calonge se proyectaba la construcción de un edificio con función de almacén y economato, con una finalidad económica y social para los colonos, pero también diseñado como punto de encuentro de los habitantes cercanos. Es más, si fuera necesario se preveía ya desde un primer momento la construcción de una capilla en este mismo enclave ${ }^{8}$.

En el Plan General de Colonización, la planificación de habitabilidad se calculó para 30 viviendas en La Verduga y 25 en Calonge, ampliables a 35 y 30 respectivamente ${ }^{9}$. Algunas de estas viviendas se encontraban totalmente aisladas, y en otras ocasiones formaban pequeños conjuntos de viviendas de hasta cuatro, pareadas y presentando nexos comunes de conformación.

En la publicación de Castañón en el suplemento Colonización de la revista Agricultura, podemos observar los dibujos de uno de estos conjuntos, concretamente los del núcleo rural de La Verduga. Aquí podemos ver unas formas constructiva que serían las seguidas por el arquitecto Francisco Jiménez de la Cruz en el diseño definitivo del poblado Calonge en 1953; juegos de volúmenes a través de presentar distintas alturas dentro del mismo conjunto residencial. Elementos sacados de la arquitectura popular y vernácula, sin una clara diferenciación local o regional, en los que vemos un cierto aire de modernidad muy matizada en los porches, y en general en las relaciones de huecos y vacíos ${ }^{10}$.

Sin embargo, en los proyectos presentados y aprobados al arquitecto García Nieto, aparece La Verduga como una población crecedera donde se plantea un hábitat semi-agrupado. Se trata de un núcleo donde se establece un grupo de viviendas y los servicios centrales, complementado con toda una serie de viviendas diseminadas por las parcelas adyacentes, que si bien en un primer momento iban a depender en muchos aspectos de la cercana Sotogordo, se proyectaba para albergar en un futuro a una población mucho mayor e independiente:

"El núcleo constará en su día de 160 viviendas de agricultores, artesanos y comerciantes, para cuyo desarrollo se ha estudiado el trazado, proponiéndose por ahora y en una primera etapa la construcción de sólo 28 viviendas para colonos con sus dependencias agrícolas y un edificio social que reúna a aquellos locales y servicios que de un modo más elemental son indispensables en toda agrupación social’11 [3].

\footnotetext{
7 CASTAÑón, ALBERTOS, G, y JIMÉNEZ VAREA: Proyecto General de Colonización..., op. cit., págs. 4854 


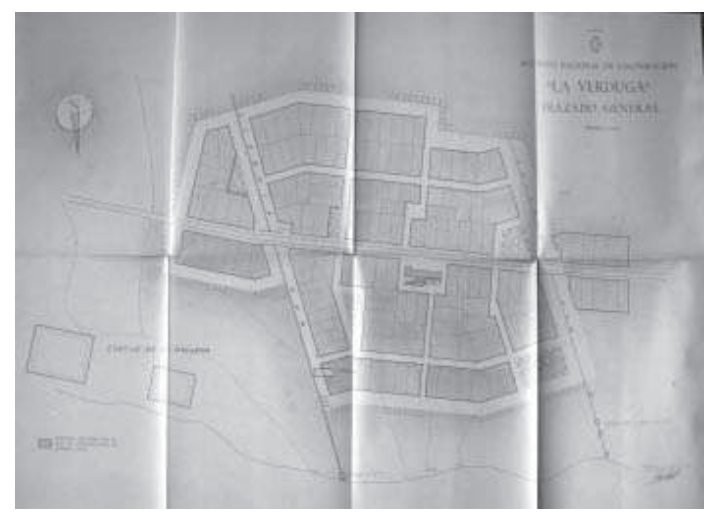

\section{La Verduga. Planta de la} Iglesia.

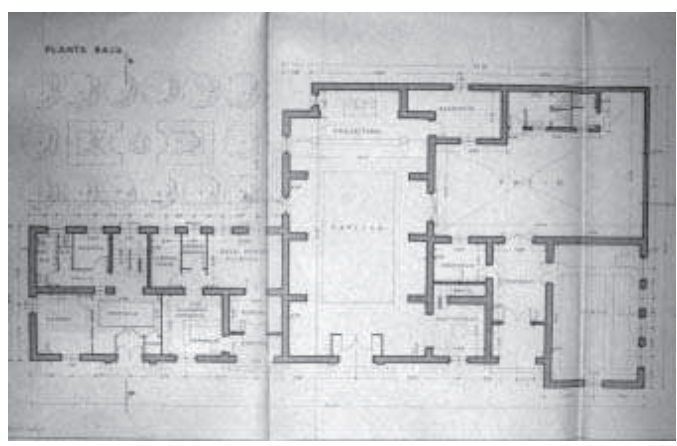

El desarrollo urbano de la población partía de un esquema muy simple con la intención de un desarrollo posterior. El caserío quedaba así agrupado entorno a una única calle que se retranqueaba para dejar espacio al edificio social formando así una pequeña plaza con un jardín.

En cuanto a las viviendas, se planificaron un total de 8 tipologías, con una disposición muy básica y sin demasiadas pretensiones compositivas, tal y como vemos en la mayoría de proyectos de esta década de los 40 en el INC. El edificio social sería el centro de la población y se componía básicamente de una capilla con su sacristía [4]. La nave constaba de tres tramos con presbiterio y testero plano. De la iglesia partían dos alas, a su izquierda el edificio se alzaba con dos plantas. En planta baja aparecían las dependencias de correos, farmacia, laboratorio y consulta médica. En la planta alta un despacho y una sala de reuniones. El ala derecha del edificio presentaba tan sólo una altura y se destinaría a las escuelas, con un aula para cuarenta alumnos, despacho del profesor y un patio.

En la segunda fase el pueblo presentaba un crecimiento que multiplicaba por cinco el número de habitantes, pero que no modificaba las dotaciones asistenciales 
básicas que se proponían desde un primer momento. El esquema urbano se volvía más complejo, manteniendo el centro en torno a la capilla y desarrollando un callejero quebradizo y desigual del que surgían pequeñas plazoletas internas y algunas exteriores en la zona del paseo de ronda.

Lo cierto es que, por razones que desconocemos, no se llevó a cabo la construcción de estos núcleos rurales dispersos. Podemos entender que a medida que pasaban los años en esta especial década de los cuarenta, donde observamos una falta de decisión en relación a las tipologías urbanas a desarrollar por el INC, se fue poco a poco optando por la concentración de las viviendas, dejando atrás las opciones parciales de dispersión. Es posible que, aunque se planificó en un primer momento tal y como se ha expuesto, llegara un momento en que el diseño de esta intervención supusiera una contradicción a las decisiones tomadas desde el propio INC en fechas más avanzadas. Especialmente desde 1949 con la aparición de las normas dictadas por el jefe del servicio de arquitectura José Tamés.

\section{SOTOGORDO.}

El nuevo pueblo de Sotogordo era esa población que además de satisfacer las necesidades básicas de sus habitantes, hubiera servido de punto de encuentro para los colonos de Calonge y La Verduga. Fue un proyecto que no llegó a realizarse, pero del que conservamos toda una serie de indicaciones que nos indican de una manera muy aproximada el aspecto y la conformación urbana que presentaba en su diseño, tanto por las indicaciones de Jiménez Varea, como del arquitecto José García Nieto, al que finalmente se le encarga la elaboración del proyecto, como en el caso de La Verduga ${ }^{12}$.

Según las indicaciones de Jiménez Varea el pueblo se situaría en las proximidades de Palma del Río (Córdoba), a unos $7 \mathrm{Km}$. de distancia, entre los arroyos Madre de Fuentes y La Verduga. En el informe detallado del Proyecto General de Colonización se establecieron algunos datos importantes a tener en cuenta a la hora de señalar el emplazamiento de esta nueva población:

Elegir un lugar sano y a ser posible en alto.

Que tenga posibilidades de abastecimiento de aguas potables.

Que su saneamiento y evacuación de aguas residuales sea fácil.

Que esté cruzado por alguna vía de comunicación importante o con fácil acceso a ella ${ }^{13}$.

En cuanto a la proyección de los poblados, se hace referencia a tres cuestiones de carácter general pero importantes y que afectaban tanto a Sotogordo como a Villalora (Sevilla) ${ }^{14}$ :

12 GARCÍA NIETO, J: Sotogordo. Anteproyecto..., op. cit.

13 CASTAÑÓN ALBERTOS, G., y JIMÉNEZ VAREA; Proyecto General de Colonización..., op. cit., págs. 49-50.

14 lb., pág. 50 
Las viviendas agrícolas necesarias para los agricultores que han de cultivar la tierra, calculando su número teniendo en cuenta que será necesaria una vivienda por cada 6 Has. Y que el radio de acción del poblado es de $1 \mathrm{Km}$. así que como para el futuro se prevé que pueden llegar a ser necesaria una vivienda por cada 2 Has.

Las viviendas para comerciantes, artesanos etc... que se construirán con el fin de facilitar y acelerar la ocupación y actividad del poblado hasta un $8 \%$ de las que se construyan para agricultores, de las cuales se cederán a los que las soliciten por su precio de coste y con facilidades de pago.

Las construcciones y servicios públicos siguientes: Abastecimiento de aguas, saneamiento, escuela, lavaderos, matadero, mercado, Ayuntamiento, casa de Falange y Sindicatos, Iglesia, cementerio, dispensario, recreo y campo de deportes.

El poblado de Sotogordo, según el planteamiento de Jiménez Varea, se disponía a lo largo del camino a Palma del Río, marcando así un eje fundamental de Este a Oeste. En el centro del poblado se encontraba la Plaza Mayor que quedaba abierta hacia el sur. La plaza era rectangular y porticada, y en ella se disponían los edificios más significativos como eran la iglesia, la Casa de la Falange, el Ayuntamiento y un edificio de recreos con café, cine y frontón para el juego de la pelota. También aparecían en la plaza el dispensario médico, la farmacia y el parador. Las casas de comerciantes se situarían en la callen principal, en las inmediaciones de la Plaza Mayor. En esta zona también iría un espacio reservado para mercado cubierto y otro para colocar los puestos al aire libre [5-6] ${ }^{15}$.

Sobre esta zona del entorno de la Plaza Mayor, podemos hacernos una idea muy aproximada de las intenciones estilísticas del arquitecto. El dibujo publicado en el suplemento Colonización de la revista Agricultura en diciembre de 1945 nos muestra una arquitectura clasicista, ligada a esa idea de recuperar elementos referenciales en nuestro pasado artístico como podían ser la pulcritud herreriana que dota al espacio de un cierto aire de pueblo castellano. Los soportales delimitan e identifican formalmente el espacio donde podemos distinguir el edificio del Ayuntamiento, que presenta y anticipa las ideas publicadas por Manuel Nasarre unos años después en cuanto a la tipología a desarrollar en este tipo de edificios ${ }^{16}$.

La iglesia muestra un volumen rotundo y pesado, reforzado por la imponente presencia de la torre estructurada en tres cuerpos. En los pies del templo aparece la fachada, diferenciada en su tonalidad por el distinto material utilizado. Ésta se presenta recorrida por altas pilastras pareadas a ambos lados de la portada. Estructura clásica, para un entorno clásico. Nada nos hace atisbar aquí ese encuentro con las tradiciones locales de los pueblos del entorno, más bien observamos ciertos deseos de reconducir esas formas.

$15 \mathrm{lb}$.

16 NASARRE Y AUDERA, M: “Ayuntamientos de España”, Reconstrucción, Marzo, n 21, 1947. 


\begin{tabular}{|c|c|}
\hline 仹 articulos & Los poblados que no existieron: Proyectos fallidos.. \\
\hline
\end{tabular}

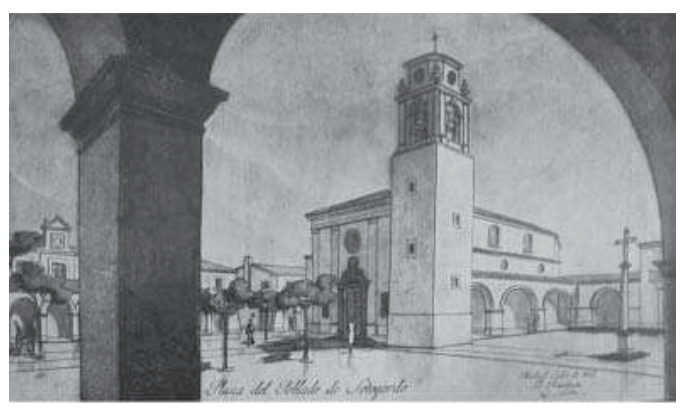

5. Sotogordo. Jiménez Varea. Revista Colonización. 1945.

6. Sotogordo. Plano. 1945.

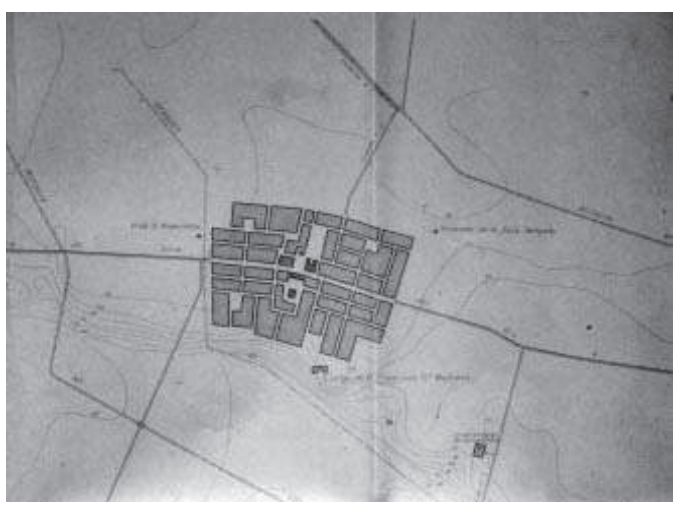

En la zona sur del poblado se desarrollaba la zona escolar, el campo de deportes, un recinto ferial y una alameda de árboles junto a los cuales se situaban los lavaderos y mataderos públicos ${ }^{17}$. El pueblo se diseñó para un número de 200 vecinos, aunque en su primera fase se realizarían viviendas para 116.

En cuanto al aspecto y la distribución de las viviendas conocemos pocos detalles de la idea que podía desarrollar Jiménez Varea. Se potencia una estética y distribución que estuviera enraizada en las tradiciones locales, con cocina-estar, tres dormitorios y una planta superior como almacén secadero. Las casas contarían con un amplio patio, con dependencias para la cría de animales y almacén para aperos de labranza y carro. Presentarían igualmente una entrada trasera desde una calle de carro ${ }^{18}$.

El planteamiento surgido del proyecto de José Nieto García es algo diferente:

"El pueblo que se proyecta contará en su día con 275 viviendas distribuidas entre colonos braceros, comerciantes, artesanos y empleados; pero la primera etapa inicial que ahora se propone solo constará de 49 viviendas de colonos con sus dependencias agrícolas; 10 viviendas de artesanos y comerciantes con sus

17 CASTAÑón ALBERTOS, G, y JIMÉNEZ VAREA: Proyecto General de Colonización..., op. cit., págs. 67-68.

18 lb., pág. 52 
locales para tiendas y talleres y dos viviendas de empleados"19.

El pueblo crece entorno a una gran plaza central. El esquema se plantea a partir de las zonas porticadas que forman la plaza, pero que también marcan un eje principal en el lateral del Ayuntamiento al prolongarse los pórticos fuera del esquema cuadrangular, creando así un paseo desde el cual se accede a la plaza. El resto de la población sigue un esquema muy sencillo en cuadrícula que en ocasiones cede un espacio para el desarrollo de pequeñas plazoletas.

La dotación de edificios para uso común e institucional era realmente completa. El pueblo dispondría de un centro cívico compuesto por la iglesia parroquial, con locales para catequesis y vivienda para el párroco ${ }^{20}$. Todos estos edificios presentan una estética cercana a la arquitectura popular pero con un cierto aire de clasicismo que no concuerda con lo vernáculo.

La iglesia presenta tres naves separadas por pilares, con cinco tramos y un presbiterio de planta ochavada. Se presenta como una totalidad junto al edificio anexo, formando un jardín interior a la manera del claustro desde el que se accede a las diferentes dependencias. En fachada aparece una torre no practicable culminada en espadaña a los pies del edificio y un frontón dominado por el gran ventanal circular [7-8].

En cuanto a la vivienda, se planteaban nueve tipos diferentes de 2, 3 y 4 dormitorios. En la mayoría de los casos con un patio-corral con una zona para almacenamiento de los aperos agrícolas. Estructuras muy simples que siguen la estética popular que se aplica en estas primeras fechas desde el Instituto.

En cuanto a las técnicas utilizadas en la construcción de los edificios señalar que éstos se construyeron con muros de tapial de zahorra y cal ${ }^{21}$. Los entramados de pisos y cubiertas eran de madera. Para cubrir se utilizó teja árabe. La tabiquería era de ladrillo colocado a panderete con revestimientos de mortero de cal y los pavimentos eran de barro cocido colocados sobre firme de hormigón ${ }^{22}$.

El caso de la cercana población de Villalora reúne las mismas características y queda englobada dentro de la misma planificación de la zona estudiada.

19 GARCÍA NIETO, J: Sotogordo. Anteproyecto..., op. cit., pág. 1.

20 Icluye también: Ayuntamiento con locales para correos, telégrafos y teléfono. Edificio social con locales para Auxilio Social, Frente de Juventudes, Sindicatos y Jefe local de FET de las JONS. Edifico Sanitario, recreativo y cultural, con clínica, farmacia, laboratorio, viviendas de médico y farmacéutico, sala de conferencias, proyecciones y representaciones escénicas. Bar-café, restaurante y círculo de agrupaciones culturales. Mercado, escuela, tiendas y talleres de artesanía popular, lavadero colectivo y un matadero.

21 La zahorra era obtenida en el lugar y se trata de una mezcla natural de grava, gravilla y arena muy utilizada en las construcciones de estos años de autarquía.

22 GARCÍA NIETO, J: Sotogordo. Anteproyecto..., op. cit., pág. 2. 


\begin{tabular}{|c|c|}
\hline 騅 & Los poblados que no existieron: Proyectos fallidos.. \\
\hline
\end{tabular}
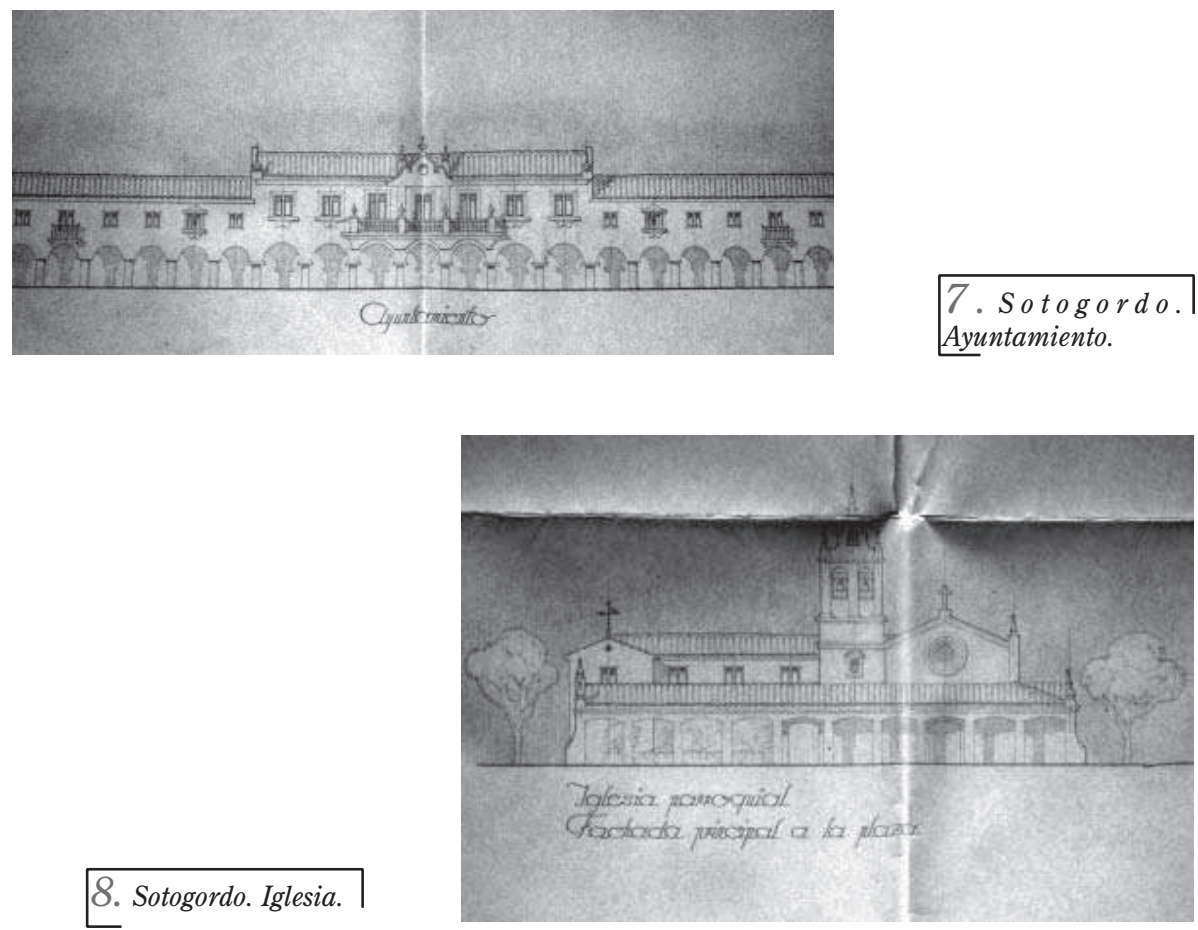

La IsLA del Rincón.

Otra zona de especial incidencia en la que finalmente no se llevó a cabo la construcción de ningún tipo de núcleo de población ni de vivienda, pero donde se señaló en un primer momento este tipo de intervención fue en la zona conocida como la Isla del Rincón. La zona está dentro de la parcela declarada de interés nacional por el decreto de 25 de noviembre de 1941, y fue considerada en su momento como de especial interés, esencialmente tras la redacción por parte del ingeniero agrónomo Antonio Pizarro Checa del Informe sobre la urgencia de la colonización de la Isla del Rincón perteneciente a la zona regable del canal de la Margen Izquierda del Rio Genil, firmado en Córdoba el 15 de abril de $1943^{23}$.

La Isla del Rincón es una extensión de aproximadamente 320 ha. enmarcada por una depresión del terreno causada por el trazado de un antiguo brazo del río Guadalquivir. Se sitúa en el término municipal de Lora del Río (Sevilla), en los límites con la provincia de Córdoba. Se trataba según los informes de Antonio Pizarro de una zona con unas potencialidades agronómicas importantes y con un proceso de

23 PIZARRO CHECA, A: Informe sobre la urgencia de la colonización de la Isla del Rincón perteneciente a la zona regable del canal de la Margen Izquierda del Río Genil. Córdoba, 15 de abril de 1943, Archivo de la Delegación del INC en Córdoba. 
transformación que no era complejo ni demasiado caro. Los habitantes de la zona eran unas 40 familias que en esos momentos habitaban en "míseros chozos".

Los problemas fundamentales para la colonización de esta zona señalados por el ingeniero eran tres: paludismo, saneamiento y control de inundaciones (especulación con los precios de las tierras). De estos problemas, el más grave parece que era el del paludismo, sobre todo en vistas a la colonización de la zona, es decir, a su ocupación humana. Antonio Pizarro señalará en su informe que "finalmente será necesario construir viviendas para la población futura ya que es inadmisible que viva en las condiciones que lo hace la población actual'24.

El informe venía a marcar una serie de puntos que se resumen en el siguiente párrafo;

"Necesidad de una especial intervención del Instituto Nacional de Colonización. La indole de los problemas planteados requieren por una parte la intervención técnica que garantice la resolución de las citadas cuestiones y por otra como las obras especialmente el saneamiento de la Madre Vieja han de ser caros dados las características y atañen con mayor o menor intensidad a toda la zona se comprenden que se salen de la esfera privada y requieren se haga cargo el Instituto Nacional, de la colonización de la Isla del Rincón en todos sus aspectos esto no significa desaprovechar la aportación que puedan hacer los particulares a quienes interese la colonización quienes podrán cooperar pero siempre subordinados a modo directo al Instituto Nacional de Colonización pues de no establecerse normas inflexibles para regular la intervención de particulares fácilmente podría desvirtuarse los fines propuestos con las fatales consecuencias que son de prever"25.

En último lugar, esta transformación se llevó a cabo a nivel agronómico dentro de otras planificaciones más tardías que conllevaron otras estructuras de colonización humanas, y no tal y como se pretendía llevar a cabo en el informe de Pizarro, es decir, como una zona independiente y no relacionada con otras fincas a transformar.

Finalmente, de todos los esfuerzos de planificación estudiados en este capítulo pocos se llevaron a cabo, y lo que se realizó es fruto de una reflexión posterior que modificó en gran medida las apreciaciones de está dubitativa década del período de autarquía. Sotogordo, Villalora y La Verduga quedaron tan sólo registrados en un puñado de documentos, al igual que los primeros diseños de Calonge que, a la postre se convertiría en un nuevo pueblo de colonización.

Los proyectos de la zona del Canal del Guadalmellato: Villarrubia, Las Quemadas, Los Mochos, El Higuerón y Rivera Alta.

Otra de las experiencias fallidas cuya planificación afectaba de una forma notable al territorio de Córdoba fue la derivada del frustrado Proyecto General de

$$
24 \mathrm{lb} \text {. }
$$

$25 \mathrm{lb}$. 
Colonización de la Zona Regable del Canal del Guadalmellato de 1945. La zona afectada por este plan es una estrecha franja que parte del embalse del Guadalmellato que discurre hasta la localidad de Almodóvar del Río. El límite superior es el propio canal y hacia el sur la margen derecha del río Guadalquivir. Se trata de la franja natural de separación entre la sierra y la campiña cordobesa.

El Proyecto General de Colonización fue encargado por el Director General del INC, Ángel Zorrilla, al ingeniero agrónomo Carlos Cremades mediante notificación de 28 de Marzo de $1942^{26}$. En esta notificación se señala la necesidad de trabajar junto a Jiménez Varea, arquitecto que en estas fechas trabajaba en las tareas de planificación del Canal del Genil. En diciembre de 1942, el Instituto cambiaría esta disposición e instaría a retomar los trabajos comenzados por Jiménez Varea al arquitecto Francisco Giménez de la Cruz que finalmente firmaría junto a Carlos Cremades el proyecto definitivo en Mayo de $1945^{27}$.

Con esta documentación, el equipo técnico se puso a trabajar en el desarrollo del proyecto presentando resultados que debemos tener en cuenta especialmente el informe sobre vivienda rural en la zona del Guadalmellato ${ }^{28}$.

Del mismo modo, en uno de los primeros apartados desarrollados en el texto de Plan General, que se detiene especialmente en la historia y evolución económica de la zona, encontramos ciertas relaciones con los proyectos desarrollados durante la $2^{\text {a }}$ República al amparo del concurso de anteproyectos que se llevó a cabo en 1932 en esta misma zona:

"Terminada la construcción del canal y parte de las acequias principales (años 1929 y 1930) surgieron las dificultades e inconvenientes característicos de las grandes zonas regables en sus primeros años de implantación del regadío, como son falta de acequias secundarias, de desagües, de preparación de las tierras para el riego, falta también de regantes especializados y de viviendas para los mismos, escasez en general de mano de obra etc.

Para tratar de remediar todas estas dificultades y en cumplimiento de la Ley de 13 de abril de 1932, el Servicio de Obras de Puesta en Riego (OPER) redactó un

26 ZORRILLA, A: Notificación interna del INC. Madrid, 28 de Marzo de 1942, Archivo de la Delegación del INC en Córdoba. Junto a esta notificación se adjuntaba una serie de materiales que eran de utilidad a la hora de realizar el proyecto. Entre ello se adjuntaba los censos de población de 1930 y 1940 de todos los núcleos de población y cortijadas afectadas por el canal, cuadros de la evolución del paludismo, índices de analfabetismo, una copia del Reglamento de la Comunidad de Regantes del Guadalmellato fechada el 17 de Noviembre de 1923 y una copia del Real Decreto de Concesión de la construcción del embalse de 13 de Noviembre de 1908.

27 CREMADES C., y JIMÉNEZ VAREA: Proyecto General de Colonización de la Zona Regable del Canal del Guadalmellato, Córdoba, Mayo de1945, Archivo de la Delegación del INC en Córdoba. El cambio de Jiménez Varea por Francisco Giménez de la Cruz se documenta en: BEATO, E: Notificación interna del INC. Córdoba, 12 de Diciembre de 1944, Archivo de la Delegación del INC en Córdoba. El proyecto se encontraba estructurado en tres sectores de actuación: Sector I, Alcolea-Las Quemadas (que iba desde el embalse hasta el arroyo del Moro). Sector II, El Higuerón (desde el arroyo del Moro hasta el arroyo de la Horca) y sector III, Villarrubia-Almodóvar (desde la Horca hasta Almodóvar del Río). La superficie total afectada era de 11.856 ha., siendo el sector II (3.868 ha.) señalado como de muy urgente realización.

28 Zona Regable del Guadalmellato. Estudio por sectores de viviendas..., op. cit. Ver: RABASCO POZUELO, P: "La planificación en la construcción de los poblados del Instituto Nacional de Colonización", Informes de la Construcción CSIC, n 515, 61, Madrid, 2009. 
Plan para la zona regable del canal del Guadalmellato. La idea general de dicho plan tenía como objeto colocar al regadío en una posición de capacidad productiva tal, que sostuviese aproximadamente una familia por 6 ha. [...]

De todas las obras necesarias para poner en marcha un regadío de esta clase y con la intensidad antes indicada, sólo existía cuando OPER inició sus trabajos en el canal principal y las acequias primarias, faltando por tanto establecer las viviendas y poblados de los nuevos colonos, los desagües, las acequias secundarias, los caminos afirmados y rurales y la adecuada preparación de las tierras para el riego. [...].

En el aspecto de la vivienda, OPER propugnaba la construcción de cinco poblados, prohibiendo en absoluto la vivienda aislada y sólo se podía edificar en la zona con autorización especial, albergues provisionales, que el propietario se comprometía a derribar tan pronto fuera requerido, hasta que fuesen construidos los citados poblados, estas medidas favorecerían el hacinamiento de la población en los viejos cortijos y dificultaban a la iniciativa privada.

Con la desaparición de aquel servicio en 1934, todos estos planes y proyectos quedaron en suspenso, no obstante lo cual los ingenieros que en los mismos tomaron parte realizaron una muy sensible labor técnica, entre las cuales destaca la redacción de los proyectos antes indicados, $[\ldots]^{\prime 29}$.

Del mismo modo, en el anejo $n^{\circ} 5$ del Plan General cabría destacar la importancia que los técnicos dan al desarrollo histórico del proceso ${ }^{30}$.

Otro de los factores que fueron estudiados con detenimiento por los técnicos del Instituto fue el de la naturaleza de los habitantes de la zona, haciendo una primera referencia a la presencia de agricultores procedentes de las vegas de Granada y de Almería que "van inyectando en la población indígena el espíritu de iniciativa, de ahorro y también de trabajo..."31, realizando análisis un tanto deshumanizados y con tintes paternalistas que sin embargo no se salían del discurso oficial imperante en el propio INC. El informe se centra especialmente en el estado sanitario de los habitantes desde una perspectiva de aplicación como fuerza elemental de transformación del territorio, señalando graves problemas como el paludismo o las fiebres tifoideas. En este sentido, se presenta un estudio realizado por el que en esos momentos era Jefe de los Servicios Antipalúdicos de la Confederación Hidrográfica del Guadalquivir, el doctor

29 CREMADES C., y JIMÉNEZ VAREA: Proyecto General de Colonización de la... op. cit., págs. 2-4, Historia y evolución económica de la Zona y de anteriores intentos de colonización.

$30 \mathrm{lb}$., anejo $n^{\circ} 5$. Entre otros documentos se encontraban de forma íntegra el censo general de población de los años 1930, 1940 y 1942, un mapa del propio Instituto sobre la defensa antipalúdica en la zona, cuadros de analfabetismo, una copia del Reglamento de la Comunidad y Sindicato de Regantes del Guadalmellato de 17 de noviembre de 1923 y una copia del Decreto de Concesión de 13 de noviembre de 1908

31 lb., hoja $n^{\circ}$ 9. Ib., hojas $n^{\circ}$ 9-10. El Dr. Peralbo establecerá una división de cinco tipos de viviendas y establecerá una serie de porcentajes para aclarar que las infecciones se dan mayoritariamente en los "chozos construidos de monte o paja, sin más ventilación que la puerta de entrada." En cuanto a las costumbres no se dan datos de ninguna práctica en particular, y sí de la falta de fe religiosa y de la imperante holgazanería y atracción por las bebidas alcohólicas de los hombres de la zona, causadas (siempre desde una visión simplista y estereotipada), especialmente por el hábito de trabajo basado en la temporalidad marcada por los cultivos de secano. La misma orientación al hablar de la educación o del espíritu de empresa de los habitantes de esta zona 
Peralbo, y que establece una relación entre los diferentes tipos de asentamientos y viviendas construidas en la zona y los casos de paludismo que se detectan ${ }^{32}$.

El estudio de los tipos de viviendas de la zona es el punto de partida para el posterior desarrollo de la planificación concreta de los nuevos poblados. Pero la referencia es indirecta, pues se trata más de detectar los elementos negativos que los positivos para no repetir errores en las nuevas viviendas. En este sentido, los técnicos establecerán dos diferenciaciones entre las viviendas construidas especialmente para los colonos por los propietarios y las viviendas preexistentes: adaptadas y chozos $^{33}$.

Las viviendas construidas expresamente para los colonos por los empresarios se distribuían con una cocina-comedor y dos dormitorios. Como dependencias agrícolas sólo tenían un almacén reducido que se utilizaba también como gallinero o cochiquera y curiosos observar cómo;

"En algunas casas de este tipo, en donde el anexo es de grandes dimensiones, se ha convertido éste por necesidades del momento en una nueva vivienda para otro colono, claro es que en peores condiciones higiénicas y de comodidad, ya que esta nueva vivienda se reduce muchas veces a una sola habitación y en el mejor de los casos a dos, separadas por un tabique de cañas que no suele llegar al techo y donde conviven personas y animales" 34 .

Teniendo en cuenta todo esto, los técnicos llevaron a cabo una nueva ordenación de la zona donde pensaron en los nuevos núcleos de población y en las viviendas.

En la zona se proyectó la construcción de dos pueblos: Villarrubia y Las Quemadas, y tres núcleos rurales de nominados Los Mochos, El Higuerón y Rivera Alta. La estructura funcional de los poblados sería la siguiente:

“... estarán dotados de su Centro Cívico correspondiente, compuesto de la Iglesia con locales de Acción Católica y la vivienda del cura, escuelas y vivienda del maestro, Ayuntamiento con todas sus dependencias, dispensario médico, y farmacia con las viviendas del médico y farmacéutico, un centrote recreo con pequeño casino, café, bar y cinematógrafo, que puede servir al mismo tiempo de Sala de fiestas y conferencias y en el pueblo de Villarrubia de un pequeño parador o posada, debido a su carácter industrial, por cuya causa también se le proyecta mayor número de viviendas de artesanos y comerciantes.

Además se construirán en estos pueblos un mercado cubierto con espacio para puestos al aire libre, matadero, lavadero, campo de deportes y cementerio con capilla.

Los núcleos rurales tendrán solamente un pequeño Edificio Social con Capilla, Escuela, Dispensario y Sala de Juntas, cuyos servicios pueden ser atendidos por el Cura, Maestro y Médico del pueblo más próximo.

En los dos núcleos más importantes se proyectan también un muy reducido

32 lb., hojas $\mathrm{n}^{\circ} 15-17$.

33 lb., hoja $\mathrm{n}^{\circ} 27$.

34 lb., págs. 27-28. 
número de viviendas de artesanos y comerciantes"35.

Para la construcción de los nuevos poblados, de los núcleos rurales y de las viviendas dispersas, se prepararon una serie de tipologías, cuatro de ellas para hábitat agrupado y una para disperso. Las viviendas las diseña Giménez de la Cruz y posteriormente sirvieron como base a muchas de las tipologías que aparecen en los poblados realizados por él.

Se eligió un solar rectangular con el lado menor de fachada principal, hecho que determina notablemente las posibilidades de conformación urbana, como nos señalaba José Antonio Gómez-Luengo, con una superficie de $450 \mathrm{~m}^{2}$ (15 m. x 30 $\mathrm{m}$. ${ }^{36}$. Las tipologías resultantes se resolvían de la siguiente manera según el Proyecto General:

Tipo A1: Vivienda de planta baja con porche de entrada y un pequeño pasillo que da acceso al comedor-cocina. Consta de tres dormitorios, despensa, porche en la parte posterior. El retrete estaba en el corral y no tenía sistema de evacuación de aguas.

Tipo A2: Constaba de dos plantas. La planta baja con cocina-comedor, con una despensa y armario empotrado. Tiene en esta planta dos dormitorios que dan a la fachada. El retrete en el corral. La planta alta estaba ocupada por un dormitorio y por un desván-granero.

Tipo A3: También consta de dos plantas, la baja con porche, cocina-comedor, despensa y un dormitorio. En la planta superior se disponen dos dormitorios.

Tipo A4: Tiene una sola planta con un porche de entrada, cocina-comedor, despensa y dos dormitorios más el retrete al que se accede por el corral.

Tipo B: Corresponde a las viviendas dispersas. Consta de planta baja y un pequeño desván. Tenía una cocina-comedor, tres dormitorios, despensa, armario y un retrete independiente al que se accede desde el exterior de la vivienda. En el porche había una escalerilla por la que se accedía al desván.

En otro punto del Plan General se establecen los futuros límites de dos términos municipales nuevos y que surgen del futuro desarrollo de estos poblados y que serían Villarrubia y Alcolea, como consecuencia del tamaño e importancia económica y empresarial que hará que esta zona tenga potestad para un ayuntamiento propio. Incluso se afirma que el resto de núcleos que no tendrán ese crecimiento dependerán de Córdoba en los casos de Las Quemadas y El Higuerón y de Almodóvar del Río en el caso de Los Mochos ${ }^{37}$.

35 Ib., págs. 39-40.

36 En entrevista personal, José Antonio Gómez Luengo nos relataba cómo las proporciones de estas amplias parcelas condicionaron de una manera determinante las posibilidades urbanas de los nuevos poblados.

37 CREMADES C., y JIMÉNEZ VAREA: Proyecto General de Colonización de la Zona Regabl... op. cit., pág.

64. 


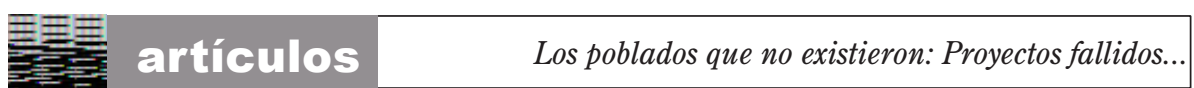

9. Villarrubia. F. Giménez de la Cruz.cpt

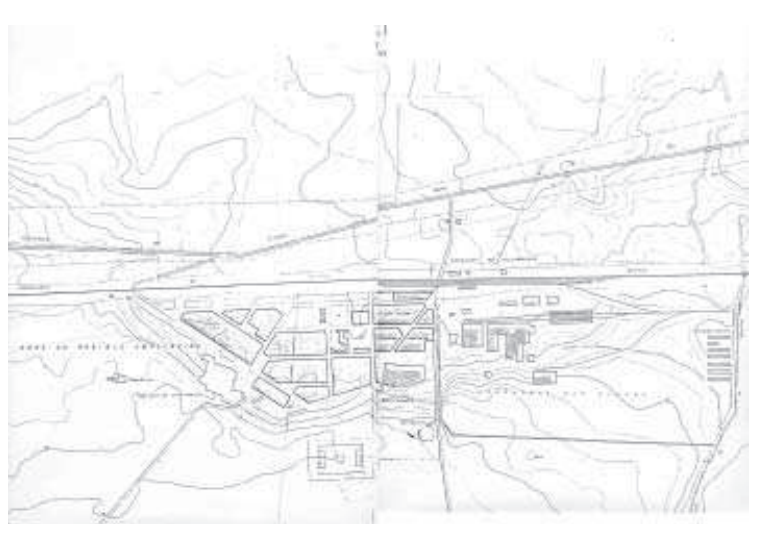

Villarrubia.

Esta zona, situada a las afueras de Córdoba, en estos momentos se había constituido como una población nueva, surgida espontáneamente por la demanda de trabajo temporal especialmente de la fábrica "Azucarera San Rafael", y donde también aparecían una serie de construcciones destinadas a abastecer a los trabajadores de la fábrica que tenían su vivienda en las cercanías de ésta. Asimismo existía una alta densidad poblacional en el cercano Cortijo de Villarrubia, con una ocupación de chozos de más de cincuenta familias [9].

El nuevo núcleo quedaba conformado por un total de 132 viviendas para colonos y 19 para comerciantes y artesanos, a construir en dos fases.

Los límites del nuevo pueblo quedaban establecidos por la propia fábrica azucarera y el ferrocarril de la línea Córdoba-Sevilla, que tenía una parada en las proximidades del nuevo pueblo. La primera fase del proyecto contemplaba la construcción de 50 viviendas de colonos y el Centro Cívico ${ }^{38}$. La azucarera quedaba de alguna forma incluida dentro del trazado del nuevo pueblo, en su límite occidental y aislada por un murete. Del mismo modo, en el proyecto se asume dentro del núcleo a la Fábrica San Isidro y algunas de las viviendas que aparecían en torno a ésta. El resto se presentaba como una prolongación de lo ya existente y siempre con el referente del ferrocarril de la línea Córdoba-Sevilla como elemento al que se abría la Plaza Mayor y en general todos los espacios y edificios públicos. El antiguo "Cortijo de los Frailes" quedaba también inserto de alguna forma en los límites del propio poblado ${ }^{39}$.

38 lb., pág. 59.

39 Ver: CREMADES C., y GIMÉNEZ DE LA CRUZ, F: Plano de emplazamiento del poblado de Villarrubia. Instituto de Cartografía de Andalucía, Sevilla. 


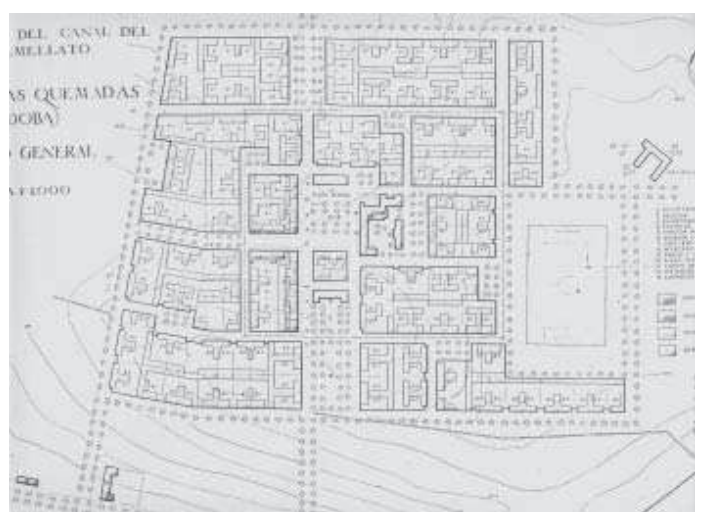

10. Las Quemadas. Plano del

\section{Las Quemadas.}

Se situaba en los terrenos del "Cortijo de Las Quemadas", entre las poblaciones de Córdoba y Alcolea, ocupando parte de las fincas de las Quemadillas, Rabanales y Valdeleches. El camino principal al pueblo era el de la carretera de Madrid a Cádiz que atravesaba el poblado constituyéndose en su calle principal. Constaría de 171 viviendas para colonos y 21 para comerciantes y artesanos. En una primera etapa se construirían 49 viviendas más el Centro Cívico [10 $]^{40}$.

El pueblo se ordenaba en función de un eje marcado por su mayor anchura en el que se iban acotando espacios para los edificios representativos, a modo de amplias plazas y paseos ajardinados ${ }^{41}$. A su vez, los edificios iban formando espacios secundarios y creando otros ejes que conectaban esta calle Mayor con las manzanas de viviendas. Éstas son de tamaño irregular y muestran la problemática de la parcela rectangular y su difícil adecuación para conseguir una regularidad en todas las calles, tratando de evitar calles recorridas por fachadas de casas y otras donde tan sólo vemos altas tapias, dando así la impresión de un espacio discontinuo. Este problema no lo salvaría Giménez de la Cruz en ninguno de sus proyectos, al no realizar una división de los tipos de vías y calles en función de su uso.

La Plaza Mayor se formaría por una serie de edificios con un porche continuo, donde encontramos la Iglesia, el Ayuntamiento, las tiendas y las artesanías, generando otros espacios secundarios donde encontramos las escuelas, las viviendas para obreros o las de maestros.

En este caso Giménez de la Cruz apuesta por diversificar los espacios mediante plazas de diferente tamaño, a costa de variar las dimensiones de las parcelas dedicadas

40 CREMADES C., y JIMÉNEZ VAREA: Proyecto General de Colonización de la Zona Regable del Cana..., op. cit., pág. 60.

41 CREMADES C., y GIMÉNEZ DE LA CRUZ, F: Plano de emplazamiento del poblado de Las Quemadas. Instituto de Cartografía de Andalucía, Sevilla. 
a viviendas y los consiguientes problemas de ordenación que eso conlleva ${ }^{42}$.

Núcleo rural El Higuerón.

Se planificaba junto a la existente estación de ferrocarril que tenía ese mismo nombre, entre Córdoba y Villarrubia. Se ordenaba el poblado a partir del cruce de dos caminos; el que partía desde la estación de ferrocarril, y terminaba en un antiguo camino que comunicaba con el cortijo "El Castilla", y el que partía perpendicular a éste desde el cortijo "El Higuerón Viejo" [11]. Sería una población diseñada con 58 viviendas para colonos y 5 para comerciantes y artesanos. Tendría como punto de enlace un Centro Social ${ }^{43}$. La disposición de éstas viviendas se hace para potenciar el eje Norte-Sur, apareciendo todos las viviendas hacia esta calle y la Plaza Mayor ${ }^{44}$.

\section{Núcleo RURAL Los Mochos.}

Se encuentra entre Villarrubia y Almodóvar del Río, en una estrecha parcela delimitada al Norte por el ferrocarril y al Sur por la carretera de Córdoba a Palma del Río. Ocupaba parte de las fincas "Los Mochos" y "El Mochuelo", pasando por sus límites la Cañada real Soriana ${ }^{45}$.

Las 62 viviendas se disponían a través de un esquema muy sencillo formado por un amplio paseo que hacía las veces de entrada al pueblo y que da acceso a la Plaza Mayor, donde se encuentra la Iglesia, las escuelas, el edificio social, y las tiendas y artesanías. Se trata de un doble eje que se cuza en este espacio representativo. Un esquema sencillo que utilizará posteriormente Giménez de la Cruz, variando en virtud del

42 CREMADES C., y GIMÉNEZ DE LA CRUZ, F: Pueblo de las Quemadas (Córdoba). Trazado General Instituto de Cartografía de Andalucía, Sevilla.

43 CREMADES C., y JIMÉNEZ VAREA: Proyecto General de Colonización de la Zo..., op. cit.

44 CREMADES C., y GIMÉNEZ DE LA CRUZ, F: Plano de emplazamiento del núcleo rural de El Higuerón (Córdoba). Instituto de Cartografía de Andalucía, Sevilla.

45 CREMADES C., y GIMÉNEZ DE LA CRUZ, F: Plano de emplazamiento del núcleo rural de "Los Mochos" (Córdoba). Instituto de Cartografía de Andalucía, Sevilla.

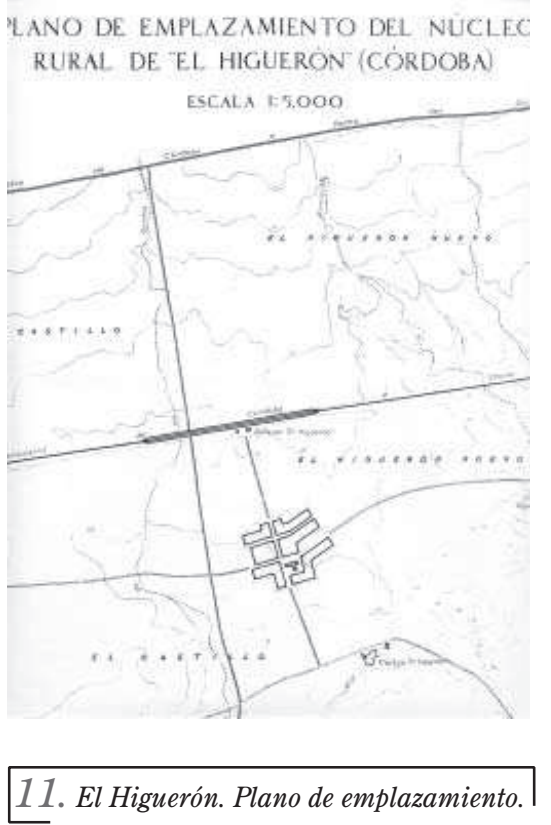




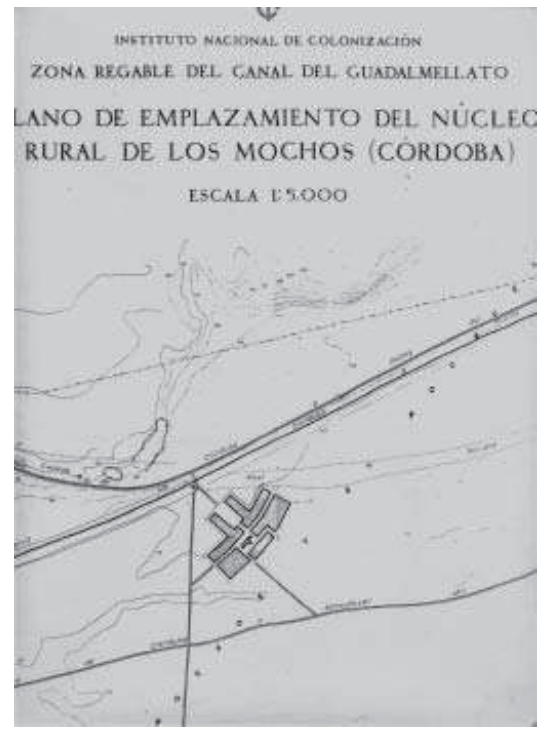

12. Los Mochos. Plano de situación.

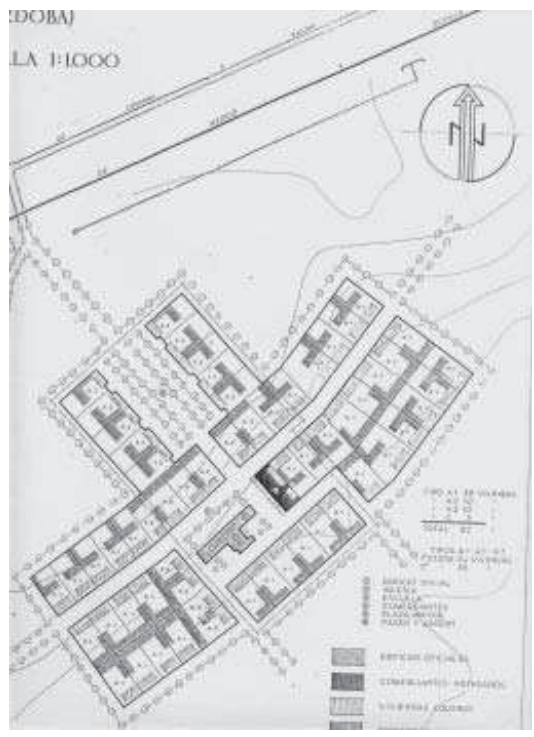

13. 13. Los Mochos. Plano del poblado.

número de habitantes que por lo general será mayor en casi todos los casos [12-13] ${ }^{46}$.

Constaba el poblado de 59 viviendas de colonos y 3 de comerciantes y artesanos, situadas todas en el edificio social correspondiente ${ }^{47}$.

\section{Núcleo rural Ribera Alta.}

Situado junto al cortijo que lleva este mismo nombre, en la zona de Alcolea, se trata de un poblado muy pequeño en el que se adelanta la estructura urbana que unos años después Giménez de la Cruz llevaría a cabo en el poblado de San Antonio [14]. Todo el caserío se dispone formando parte de esa Plaza Mayor en la que aparecen la Iglesia, el centro social y las escuelas. Las dependencias del antiguo cortijo "Ribera Alta" se aprovechan para edificios comunales de carácter agrícola, como una gran zona para el criado de gallinas, pajar, tinado, almacenes o cuadras. Presentaba 32 viviendas para colonos y un edificio social ${ }^{48}$.

46 CREMADES C., y GIMÉNEZ DE LA CRUZ, F: Plano del trazado general del núcleo rural de "Los Mochos" (Córdoba). Instituto de Cartografía de Andalucía, Sevilla.

47 CREMADES C., y JIMÉNEZ VAREA: Proyecto General de Colonización de la Zona..., op. cit. Tenía 39 viviendas del tipo $A 1,10$ del tipo $A 2,10$ del tipo $A 3$ y 3 del tipo $C$.

48 lb., pág. 60. Se realizan 15 viviendas del tipo A1, 6 del tipo A2 y 11 del tipo A3. 
LOS PROYECTOS NO REALIZADOS EN LA ZONA DEL BEMBÉzAR.

No son muchos los datos que tenemos sobre los proyectos de ampliación de Peñaflor y de Lora del Río así como de la construcción de los nuevos pueblos de Velásquez y Sotillo de Moratalla, salvo que aparecen citados en diferentes documentos del Plan General de Colonización de la Zona del Bembézar, en el Plan Coordinado de Obras de la zona del Bembézar y en las diferentes normativas que se publicaron. El hecho es que finalmente estos proyectos no se llevaron a cabo.

Tan sólo podemos señalar que en la $2^{\mathrm{a}}$ parte del Plan Coordinado de Obras de la Zona Regable del Bembézar, se habla de la construcción de un nuevo pueblo llamado Velázquez en el sector

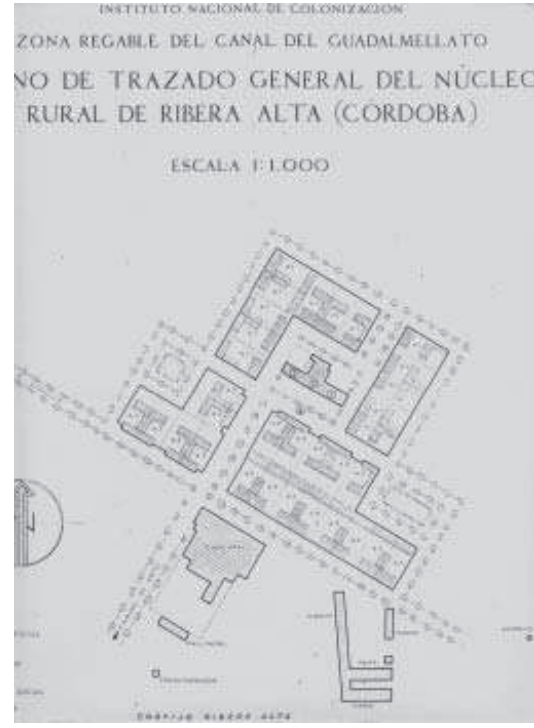

14. Ribera Alta. Plano del poblado. XI que estaría situado a unos cinco kilómetros al Oeste de Lora del Río, al Norte de la carretera A-431. El proyecto inicial se tenía que haber presentado en septiembre de 1960 para concluir las obras en noviembre de 1962. Del mismo modo, las ampliaciones de Lora y de Peñaflor tenían que haberse llevado a cabo entre los años 1959 y $1961^{49}$.

En el caso de Sotillo de Moratalla, el proyecto se tenía que presentar en octubre de 1957, para entregarse las obras enero de $1959^{50}$. Pertenecía al sector IV de la zona del Bembézar, en una zona en la que se planificaba y en este caso también se construía el nuevo pueblo de Mesas de Guadalora.

49 BOE, $n^{\circ} 128$, de 14 de mayo de 1957. Orden conjunta de los ministerios de Obras Públicas y de Agricultura, de 23 de abril de 1957 en la que se aprueba la $2^{a}$ parte del Plan Coordinado de Obras de la Zona Regable del Bembézar.

50 BOE, $n^{\circ} 101$, de 12 de abril de 1957. Orden conjunta de 23 de febrero de 1957 por la que se aprueba el Plan Coordinado de Obras de la zona regable del Bembézar (Córdoba). En Madrid, 23 de Febrero de 1957. Orden firmada por los directores generales de Obras Hidráulicas y Colonización: Suárez de Tandil y Cavestany. 
